\title{
Kill or Be Killed
}

\section{Ed Brubaker y Sean Phillips}

Panini, 2018

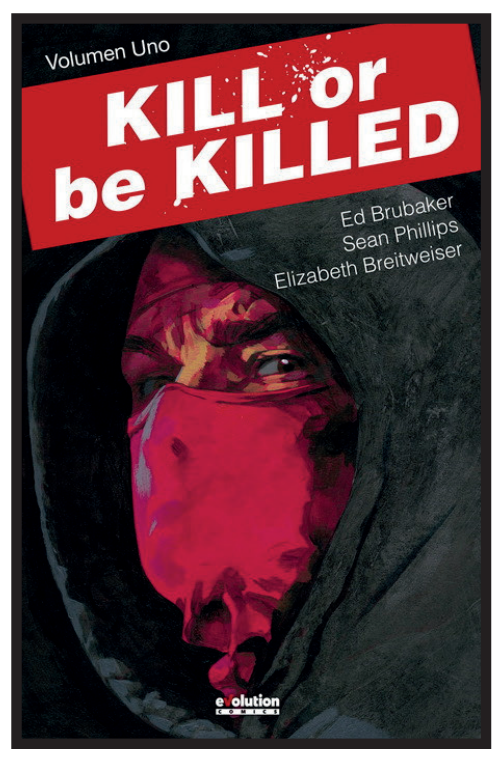

n poco más de tres lustros, el tándem Brubaker/Phillips se ha convertido en una de esas alianzas creaLtivas de referencia del noveno arte. De ellos no es concebible ya una obra mala, ni tampoco la comodidad. Su ligereza a la hora de dar cierre o poner en pausa indefinida a series de éxito demuestra su voracidad creativa. A nadie le importaría que los últimos diez años los hubieran dedicado en exclusiva a desarrollar el universo Criminal, pero, gracias a que no lo han hecho, pudimos disfrutar de las magníficas Incognito, Fatale, The Fade Out y la que nos ocupa, Kill or Be Killed. Siendo muy diferentes, existe un elemento transversal a todas ellas, que podríamos considerar la espina dorsal temática en la obra del dúo: la obsesión por la cultura de derribo surgida a lo largo del siglo xx, particularmente aquellas manifestaciones previas a la explosión ultra mainstream finisecular. La literatura de terror, los pulps, los tebeos de superhéroes, la novela negra hard boiled, el Hollywood dorado... En este sentido, podemos considerar Kill or be Killed el summum de esta fijación subcultural, pues condensa los hallazgos de sus predecesoras, con el plus de que todo ello es aplicado en un contexto de rabioso «aquí y ahora» para con la primera remesa millennial, los nacidos a lo largo de los ochenta.

El punto de partida de la historia viene a ser: Dylan, un estudiante universitario «de largo recorrido» que está pasando por el pico de una de sus fases depresivas, decide suicidarse precipitándose desde la azotea de su edificio. Sobrevive a la caída y con ello se da cuenta de que, a pesar de todo, quiere vivir. Más tarde descubre que el milagro ha sido obra de la providencia diabólica, y que su demonio salvador desea ser retribuido con un sacrificio humano mensual. O eso o el muerto a fin de mes será el propio Dylan. Matar o morir, Kill or be killed. Y ya que tiene que hacerlo, alimentará al demonio con aquellos que «se lo merezcan».

Lo dicho, puro pulp, pero con mucho valor añadido de por medio. Para empezar, el interés de Dylan por la literatura, convenientemente aprovechado a través de abundantes monólogos interiores y rotura de la cuarta pared, aporta al tebeo una potente dimensión metalingüística. Dylan está planteándose continuamente su propio devenir en términos de análisis 
narrativo y cultural. Al contrario que la mayoría de los vigilantes de ficción, el nuestro es una persona muy leída y que además hace lo que hace por pura supervivencia y en contra de su voluntad... o no, dado que él mismo se encarga de poner sobre la mesa la teoría de que todo el asunto del demonio es un producto de una posible deriva psicótica.

El bagaje cultural y la capacidad de análisis de Dylan, sin embargo, no le han servido para evitar una situación vital desastrosa, sustentada en las malas decisiones, la culpa y el bloqueo. Como cualquier joven con, digamos, inquietudes, te puede razonar lo mal que funciona el mundo y cómo hemos terminado en una sociedad con poco margen para la esperanza. Cabeza muy bien amueblada a nivel macro, en un área dónde el peso de la responsabilidad propia es pequeño, pero poco útil cuando se trata de finalizar los estudios o liarse con su amiga de toda la vida en el momento idóneo para que los dos se sientan extremadamente miserables por ello. De algún modo, sus aventuras como justiciero enmascarado pueden verse como una desquiciada huida a su zona de confort, a una realidad «de género» parametrizada por unos códigos que él maneja a la perfección; con el añadido de que, en ese nuevo contexto a medida, realmente puede arreglar el mundo, aunque sea solo un poco.

En muchos aspectos, el Dylan de Kill or Be Killed puede verse como la contrapartida millennial al Travis Brickle de Taxi Driver (Martin Scorsese, 1977). Con veintiséis años, Brickle es totalmente autosuficiente, no dispone de estudios superiores, había combatido en Vietnam, y sus inquietudes como vigilante en ciernes se reducen a «limpiar la basura de las calles», una idea surgida de su propia experiencia pasada por el filtro de la paranoia y la desinformación, de las conclusiones que saca cada noche desde su taxi. A los veintiocho años, Dylan todavía sigue en la universidad, nunca ha tenido contacto con la violencia (mucho menos en una guerra), y ejerce su cruzada desde la óptica de la justicia social. En última instancia (veremos como se desarrolla el tema del demonio en próximas entregas) ambos personajes podrían verse impulsados a hacer lo que hacen por algún tipo de desequilibrio psicótico, pero si Brickle es seguro de sí mismo, osado y resolutivo (también en lo romántico) desde el principio de su historia, Dylan empieza consumido por una ansiedad bloqueante, y solo cuando (¿cree que?) la muerte le acecha puede empezar a salir de ese bucle que lo inhabilita. Que esa nueva fase de su vida resulte todavía más destructiva que la anterior, ya es otro cantar...

Volviendo a lo pulp, existe otro elemento de ese palo que aporta una poderosa personalidad gráfica y metafórica a la serie: el padre de Dylan y su arte. Con una historia de ilustrador comercial frustrado, acaba recayendo en el negocio del erotismo gráfico, trabajando para revistas de mala muerte en las que plasma toda la oscuridad que lleva dentro: escenas sadomasoquistas ambientadas en mundos magmáticos fluidos poblados de todo tipo de lascivas criaturas infernales. Dylan convive furtivamente con esa imaginería a lo largo de su infancia, y, de alguna manera, la hereda como marco simbólico de su propia oscuridad interior. Pese a que esas pinturas aparecen muy ocasionalmente en la diégesis de la narración, si las sumamos a un inteligente diseño del color en el que el rojo se aplica a elementos muy puntuales pero cruciales (la máscara, las explosiones sangrientas, el fondo de las portadas...), es inevitable para el lector no ver el mundo de Kill or Be Killed (esto es, el mundo de Dylan) como un volcán relleno hasta los topes de lava y a punto de entrar en erupción. Curiosamente, 
podemos encontrar un efecto parecido aunque mucho menos sutil en el reciente y celebrado film Mandy (Panos Cosmantos, 2018).

En el momento de escribir este texto, Kill or Be Killed empieza su recorrido editorial en España con la publicación del primer volumen por parte de Panini, pero la serie ya ha finalizado en EE. UU.: veinte comic-books agrupados en cuatro tomos recopilatorios. Una vez más, la mesura ha tenido prioridad frente al estiramiento indefinido de un título de éxito. Mucho se tendrían que torcer las cosas en lo que nos queda por leer para que esta obra no se convierta en otro hito de la imparable carrera de sus autores hacia el Olimpo del cómic.

David Rodríguez Mosteiro

David Rodríguez Mosteiro (Melide - A Coruña, 1978) es ingeniero de telecomunicación por la Universidad de Vigo y se gana la vida como desarrollador de aplicaciones. Bajo la identidad secreta de Intramuros, navega sin descanso por los confines de la cultura pop, registrando sus hallazgos en intramuros.es y otros espacios de Internet. 